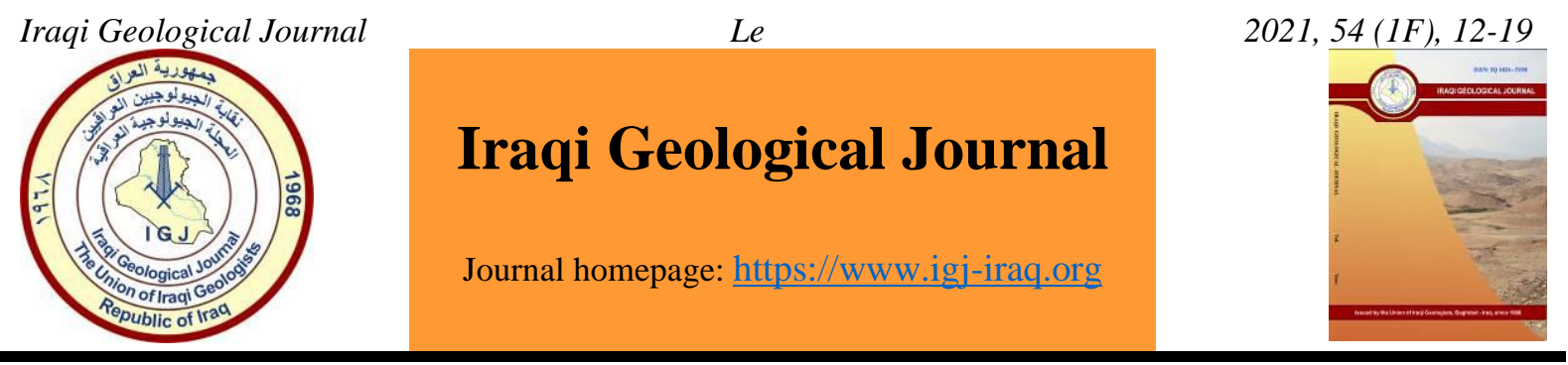

\title{
Evolution of Deep-Water Sinuous Channel Offshore Cameroon, West Africa, Using 3D Seismic Data
}

\author{
Anh Ngoc Le ${ }^{1, *}$ \\ 1 Hanoi University of Mining and Geology, Vietnam \\ * Correspondence: lengocanh@humg.edu.vn \\ Received: 30 March 2021; Accepted: 11 May 2021; Published: 30 June 2021
}

\begin{abstract}
Using newly acquired 3D seismic data, the deep-water sinuous channel has been discovered in the Miocene sequence on the continental margin of Cameroon, West Africa. The investigation is using high-resolution 3D seismic data, covering an area of $1500 \mathrm{~km}^{2}$, with the water depth ranging from $400 \mathrm{~m}-2000 \mathrm{~m}$. Two submarine channel systems have been documented in the northern part of the study area, the offset stacked channel and North-Northeast - Southwest channel. The offset stacked channel dimension is about $3 \mathrm{~km}$ wide, c. $20 \mathrm{~km}$ long and c. $500 \mathrm{~ms}$ TWT thick, extending from east to west. The evolution of this channel can be divided into three stages based on the changes in channel scale, geometry, and fill type. In the initial stage, the channel is characterized as symmetry ' $U$ ' shaped, bidirectional onlap, high amplitude reflections, inferring to high energy flow and sand-prone channel fill. In the following stages, the channel reduced the size and flow energy. NorthNortheast - Southwest channel developed at the end of the Miocene. It is c. $3 \mathrm{~km}$ wide, $20 \mathrm{~km}$ long, $50 \mathrm{~ms}$ TWT thick, indicating a new sediment source for the study area. At the end of the Miocene, both channel systems show a high sinuously as an indicator of low energy flows. Uplift in the Late Miocene possibly leads to the compacted channel complex which is appeared in the anticline form, giving a great hydrocarbon trap potential for the study area.
\end{abstract}

Keywords: Deep-water channel; Sinuous channel; Offset stacked channel; Miocene channel; Offshore Cameroon

\section{Introduction}

With the development of high-resolution 3D seismic techniques, nowadays, deep-water processes have a much better understanding. The interest in the submarine channel, the main element to transport material from shallow to deep water, has got more attention lately (Posamentier and Kolla, 2003; Gee and Gawthorpe, 2006; Gee et al. 2007; Macauley and Hubbard, 2013). In West Africa, submarine channels have been documented in offshore Angola (Gee and Gawthorpe, 2006), Congo (Gay et al., 2003), and th e Niger delta (Zhao et al., 2018). They are often characterized as channel complex with levees. Sinuous channels in the deep-water setting have been suggested similar to fluvial channels but more variable and complex (Kolla et al. 2007; Lazim et al. 2020). Deep-water channels have a different style and internal architecture. The channel shifts or migrations are in form of lateral migration to vertical aggradation, which is the result of relatively continuous erosion with discrete cut and fills or

DOI: $10.46717 /$ igj.54.1F.2ms-2021-06-22 
episodes of distinct and discrete channel cut and fills (Imran et al. 1999; Kolla et al. 2007). The degree of sinuous channels is supposed to be controlled by flow parameters and sediment grain size in space and time (Kolla et al. 2007). Most channels in the deep-water system are characterized as meander-loop migrating with down-system drift and aggradation pattern overall (Posamentier and Kolla, 2003). The study area is located in deep-water offshore Cameroon, with a water depth range from 400 to $1900 \mathrm{~m}$ (Fig. 1). This is a new exploration area, thus, the full basin evolution and stratigraphy of the basin is still unrevealed. Aggradation Pliocene-Pleistocene submarine canyon system has been documented in the high gradient slope area to the east by Le et al. (2015). These authors indicated that the sedimentation of shallow sequences is mainly sourced from east and northeast. Using recently acquired 3D seismic data, this paper will first time describe newly discovered Miocene channels in the deep-water slope of the Cameroon margin in West Africa. A detailed analysis of the paleo-submarine channel is presented with insight into their geometry and process give a better understanding of the depositional system and also the reservoir potential in the area.

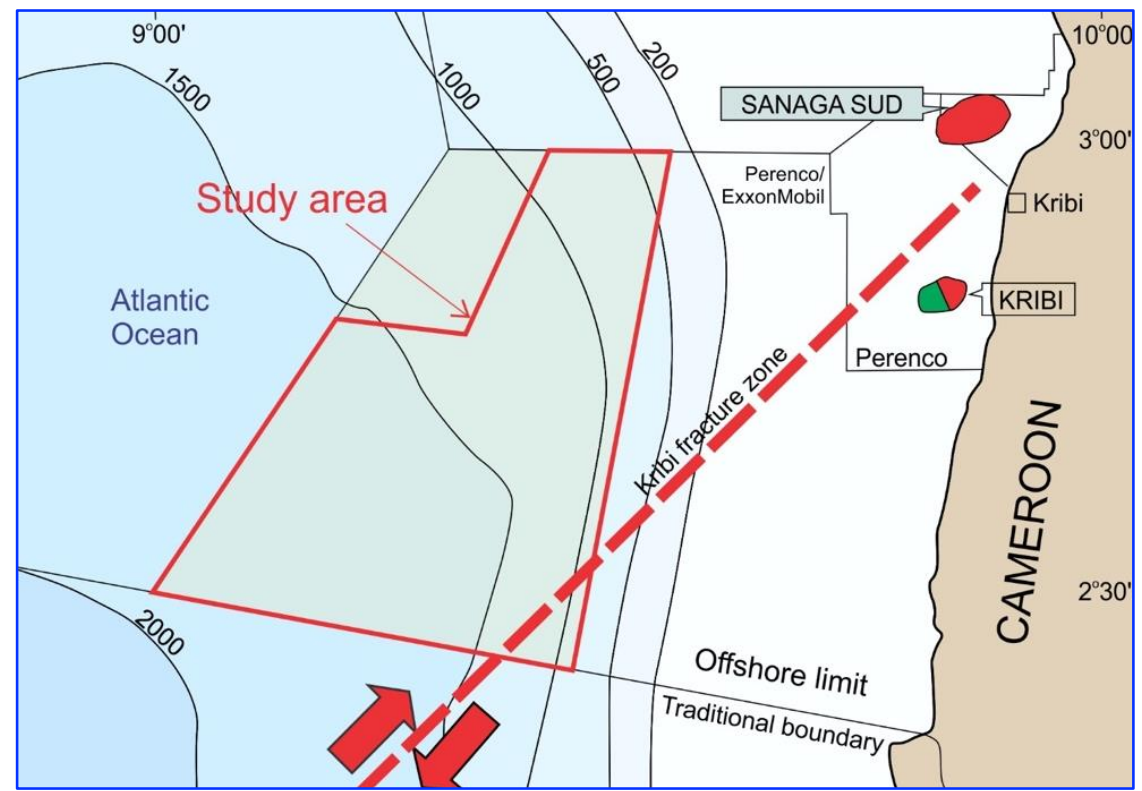

Fig. 1. The study area is located in deep-water, offshore Cameroon, covering an area of $1500 \mathrm{~km}^{2}$ (Internal report of sterling, 2012)

\section{Regional Geology}

The study area is located in the deep-water area of the Kribi-Campo sub-basin, on the continental slope, covering an area of $1500 \mathrm{~km} 2$, with the water depth range from $400 \mathrm{~m}$ to $1900 \mathrm{~m}$. The slope gradient is c. 2o upslope and 1.3o downslope. The basin is one of a series of Early to Mid-Cretaceous rift basins (Dailly et al. 2002). The basin is in the zone trending northeast-southwest. Basin evolution was divided into several phases: (1) Early rifting in Mid to Late Aptian formed series of listric faults associated with roll-over anticlines, (2) Early gravity sliding from Albian to Coniacian created rotated fault blocks, (3) inversion and folding in Santonian, (4) Tertiary uplift episodes resulted in gravity sliding in early, Mid andLate Tertiary (Lawrence et al. 2002) (Fig. 2). In this area, gas hydrate and submarine fans have been documented in the Pliocene and Pleistocene sequences (Le et al. 2015; Le, 2021b). The evolution of the submarine channel and fan shows the controls of Kribi High in the southeast. The development of intensive striation at the base of the submarine fan was interpreted for the high sedimentation rate in Pliocene time (Le, 2021b). In Miocene, the basin is a fully marine environment. The development of Miocene submarine channel complex has been documented in the 
Angola continental slope with the control of salt structure (Gee and Gawthorpe, 2006), creating a large transportation network to transport sediment basin ward, up to $200 \mathrm{~m}$ thick and more than $5 \mathrm{~km}$ wide (Abreu et al., 2003). The Tertiary sequence comprises a series of marine mudstone-dominated sequences with inter-bedded sandstones and limestones (Dailly et al. 2002).

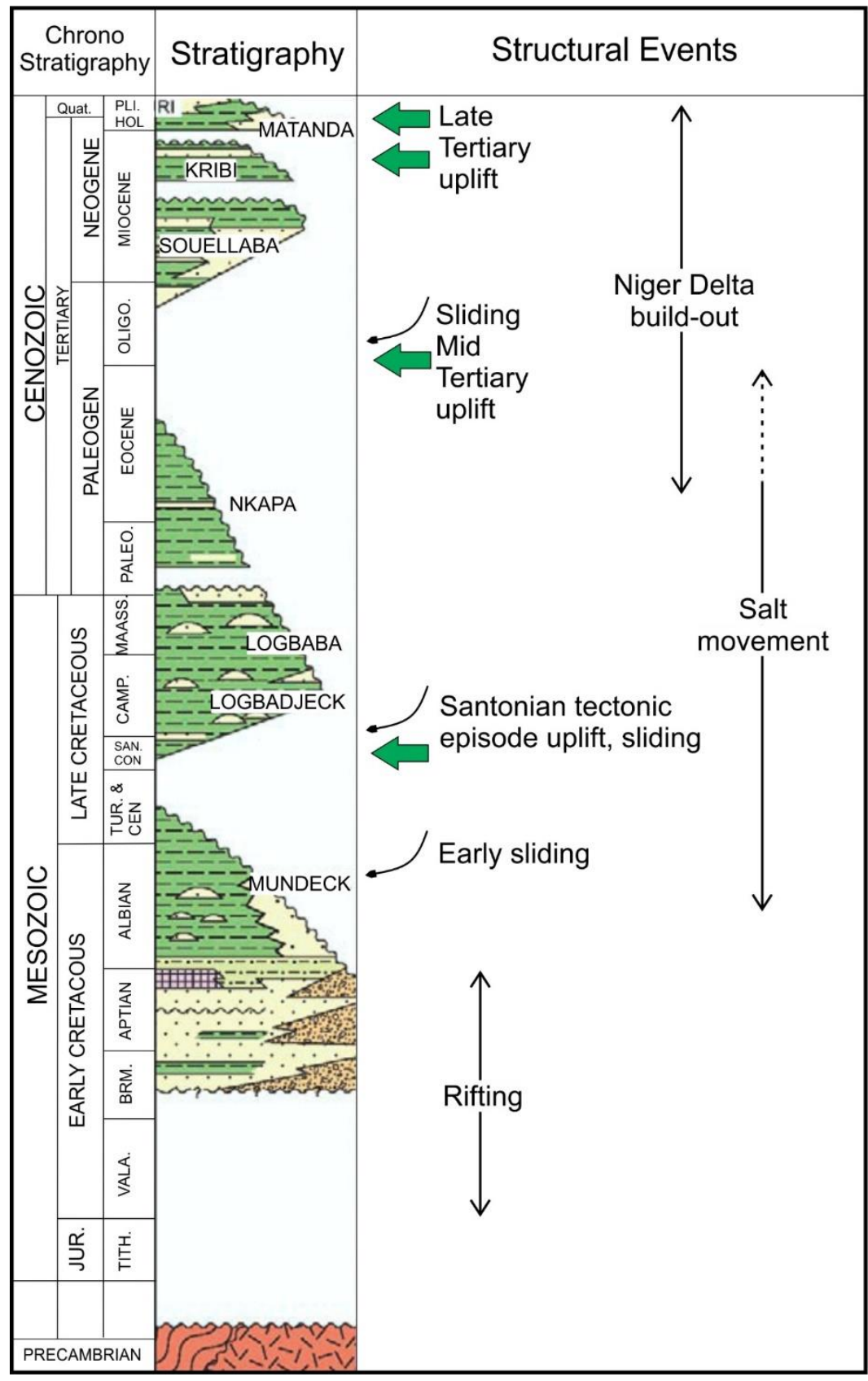

Fig. 2. Regional tectono-stratigraphic chart of Douala basin. The tectonic episodes are marked by regional significant unconformities in Santonian and Mid, Late Tertiary (Lawrence et al., 2002)

\section{Materials and Methods}

This study using high-resolution 3D seismic data, covering an area of $1500 \mathrm{~km} 2$. The seismic data was acquired with line spacing of $12.5 \mathrm{~m}$ and up to $6.6 \mathrm{~s}$ TWT below the seafloor. This study focused on the interval from $2500 \mathrm{~ms}$ to $3500 \mathrm{~ms}$, corresponding to the Miocene section. The seismic data is in zero phase displayed in seismic default color, as red, yellow, or orange corresponds to positive polarity 
and light blue to negative polarity. There is no well data in this area to give the velocity model, therefore, the time-depth conversion could no proceed. When the depth or thickness are quoted, it will be referred to time-domain in milliseconds. The seismic interpretation was carried out using the Schlumberger ${ }^{\mathrm{TM}}$ Petrel software. Seismic interpretation has been carried out using a manually picked fine interpretation grid; followed by auto-tracking where there is a good quality surface. Thickness maps, Root Mean Square (RMS) attribute maps were generated for some key surfaces to facilitate detailed submarine channel analysis.

\section{Results}

The Miocene sequence is bounded to the base and top by key surface KS-2 and KS-3, respectively (Fig. 3). The base of the Miocene (KS-2) is characterized by a strong negative reflection disrupted by polygonal faults in the southern area where the slope gradient is high (Fig. 1). The surface is the upper boundary of high-density polygonal fault successions (Le, 2021a). The top of Miocene (KS-3) was identified as continuous, strong negative amplitude reflection. The surface marks the top of offset stacked channels (Fig. 3). Miocene sequence is characterized by low to high amplitude, good to fair continuity, sub-parallel reflections. Unit thickness ranges from $150 \mathrm{~ms}$ to $450 \mathrm{~ms}$ TWT. Two channel systems have been discovered in the northern area including offset stacked channels and N-NE - SW channels (Figs. 4 \& 5). While the offset stacked channel shows a long-term development in the entire Miocene, the N-NE-SW channels developed in the Late Miocene.

\subsection{Offset Stacked Channels}

Offset stacked channels is a channel complex system observed in the northern study area displays as aggradational stacked channels with a long-term evolution from the early to Late Miocene (Fig. 4c). Detailed analysis of this complex channel system reveals that there are three stages of the channel evolution (Fig. 6). The first stage is initiated by a first major cut creating an erosional base of the channel complex, incised into the substrate (red line in Fig. 6). The channel has symmetric ' $U$ ' shaped and the initial erosion is about $50 \mathrm{~ms}$ TWT and that is deep enough for the deposition of high amplitude seismic reflections which is interpreted to be the sandy channel fill. The channelized deposits in this stage are characterized by cut-and-fill architecture, expressed as high amplitude, bi-directional downlap reflections (Fig. 4). The channel is about $250 \mathrm{~ms}$ TWT thick and c. $3 \mathrm{~km}$ wide. The channel facies show aggradation which is associated with the levees. The levees express as an aggradation levee system with a total levee thickness of $150 \mathrm{~ms}$ TWT. The levee high is gradually decreasing away from the channel, expressing low amplitude reflections, inferring to the mud-prone sediment. Following the first stage, the second stage is marked by the second major cut (Figs. $4 \& 6$ ). This stage is defined by the abrupt change in the channel style, from symmetric ' $U$ ' shaped to asymmetric ' $U$ ' shaped, high amplitude to moderate -low amplitude seismic reflections, from leveed channel to completely absent or unrealizable on the seismic. Moreover, the channel fills are characterized as aggradational convex-up high amplitude reflections on the left and almost transparent to the right (Fig. 4c). Low amplitude, transparent amplitude reflections is interpreted to be mud-prone channel fills. The channel in this stage is almost the same size as stage one but dominantly filled by sand-prone on its left side and mud-prone on its right side. In stage three, the channel is significantly narrower than stage two, reducing its size to one-third. The channel size is about $1 \mathrm{~km}$ wide, $150 \mathrm{~ms}$ TWT thick, and $20 \mathrm{~km}$ long. The channel facies is characterized as convex-up, high amplitude reflections which are interpreted to be sand prone. This stage is marked by two high amplitude, relatively continuous seismic reflections at is top and base S2 and S1 surfaces, respectively. The geometry of the channel is revealed on the maximum amplitude map of $50 \mathrm{~ms}$ above the S1 surface (Fig. 4a). The significant distinguish of this stage from others is that the channel system 
shows its high sinuosity. The channel also appears sinuosity on the maximum amplitude map between surface S1 and S2 (Fig. 4b). The levee is absent and the flow is possibly completely confined within the erosional wall of the channel. Overall, the offset stacked channel system is a large-scale channel. It has a long-term development during Miocene time with different cuts and fills. The channel is lateral shifting to the north and increasing its sinuosity upward. The channel-levee system developed in the early stage and almost absent in the subsequent stages. Channel-fill deposits are characterized as high amplitude reflections which are interpreted to be dominantly coarse-grained sediment, sand-prone.

\subsection{North-Northeast - Southwest Channel}

The isochron map of reflection S1 and S2 reveals that in the northern area where channels occurrence, the thickness to the east tends to be thinner than the west. In this thicker area, there is another channels system developed trending N-NE - SW. This channel is displayed in the maximum amplitude map between surface S1 and S2. The channel develops at the end of the Miocene time. In the crosssection, the channel appears as a ' $U$ ' shaped, filled by moderate to high amplitude reflections. These high amplitude reflections exhibit a sinuous pattern in plan-view, extending from north-northeast to south-west, and crosscut the offset stacked channels. It has dimensions of c. $3 \mathrm{~km}$ wide, $20 \mathrm{~km}$ long, 50 ms TWT thick, and is interpreted to be another channel pattern coming from the NE, suggesting another sediment source in the Late Miocene.

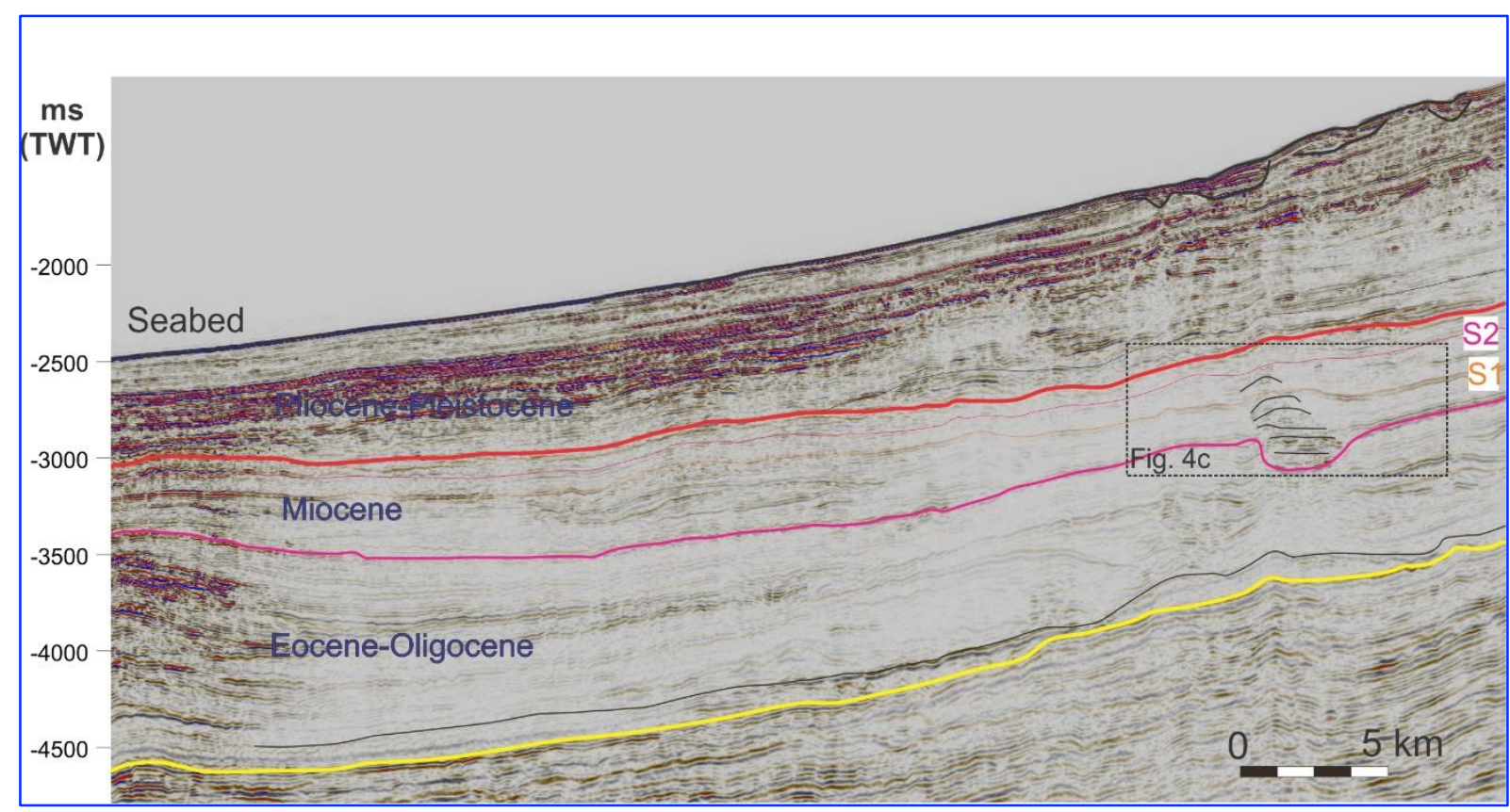

Fig. 3. Seismic line illustrates Tertiary sequences (see the line location in Fig. 1). The Miocene channel system is described in detail in Fig. 4

\section{Discussion}

The offset stacked channel complex had a long-term evolution in almost the entire Miocene time. During this period, the channel shows the changes in the processes. According to Kolla et al. (2007), three main processes are controlling the channel evolution i.e., erosion, by passing, and deposition. The interaction between these factors will define the way channel evolution as lateral migration aggradation or vertical aggradation. The channel complex has experienced three stages of evolution. Each stage change is likely caused by the major change of flow regime and type of sediment loading (Posamentier 
and Kolla, 2003). According to these authors, the wide exhibition of the channel in the first stage is possibly interpreted to be higher energy turbidity flow deposits than the following stages. This is a longterm flow. Subsequently, the second stage is characterized as vertical aggradation fills indicate a decrease in flow energy with occasionally high. The narrower and highly sinuosity channel in stage three suggested a period of low flow energy. In terms of hydrocarbon exploration, particularly from a reservoir quality standpoint, if the sandstone channel fill is completely confined within the erosional walls, then these sands may not connect directly with the levee sediments, thus form isolated flow units (Posamentier and Kolla, 2003). Also according to these authors, aggradation channel systems where sandy channel fill is associated with levee walls will create a single flow unit. In this study, the offset stacked channel is filled with high amplitude reflections, interpreted to be sandy channel fill. In stage one, the development of the levee system and high energy flow results in the sand-prone channel fill which is possibly confined within the incised channel wall and also contact with the levee wall. The incision is c. $50 \mathrm{~ms}$, thus there will be possibly the existence of both contacts. The flow unit associated with the offset stacked channel, therefore, can be defined as a single flow unit in stage one and change to isolated flow units in the following stages. The long-term development of offset stacked channel has experienced an uplift in Late Miocene which was recorded by the convex-up channel fill reflections (Fig. 2). This late tectonic event creates an anticline trap, giving great hydrocarbon trap potential for the study area.

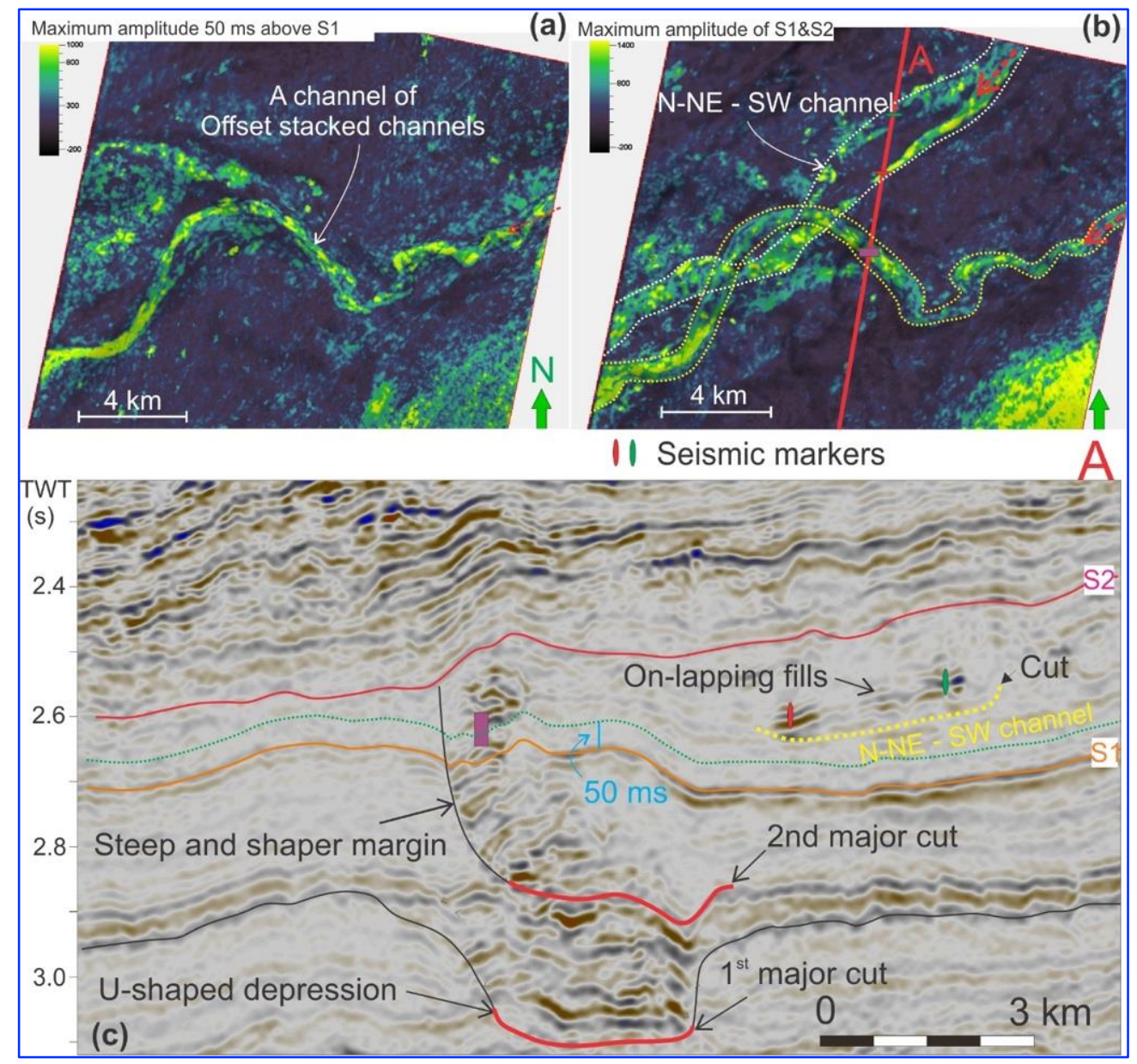

Fig. 4. Complex channel migration (a) Maximum amplitude map of 50ms above the $\mathrm{S} 1$ surface reveals the offset stacked channel system. (b) Maximum amplitude map of S1 \& S2 surfaces showing two channel systems driving from east and northeast. See the location of the map in fig 5. (c) The seismic section illustrates two channel systems, offset stacked channel and N-NE - SW channel 


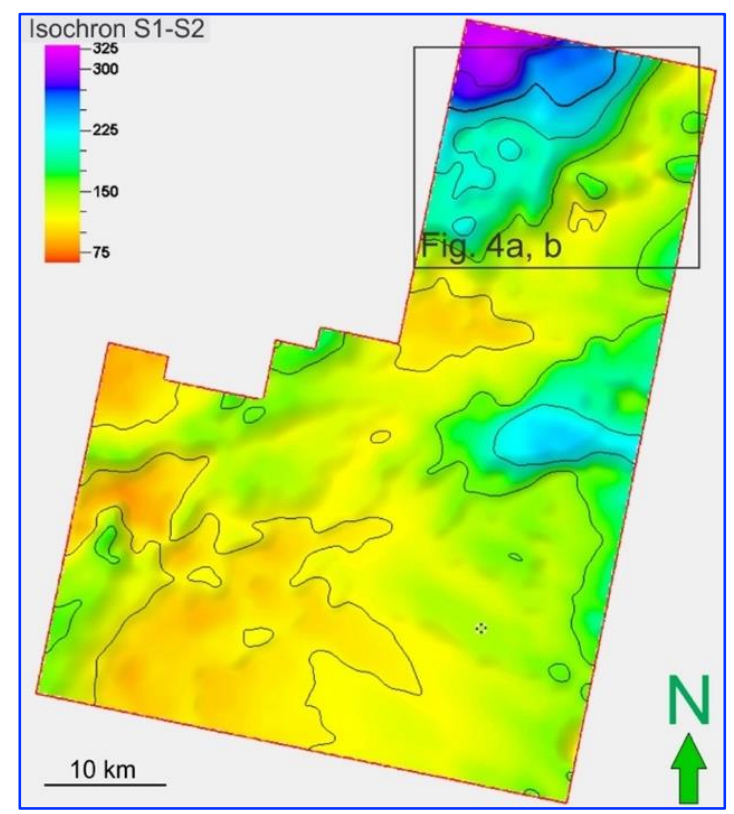

Fig. 5. The isochron map between surfaces $S 1$ and $S 2$. The area developed an offset stacked channel is indicated in Fig. 4a, b with the thickness varies from $100 \mathrm{~ms}$ to $300 \mathrm{~ms}$ TWT

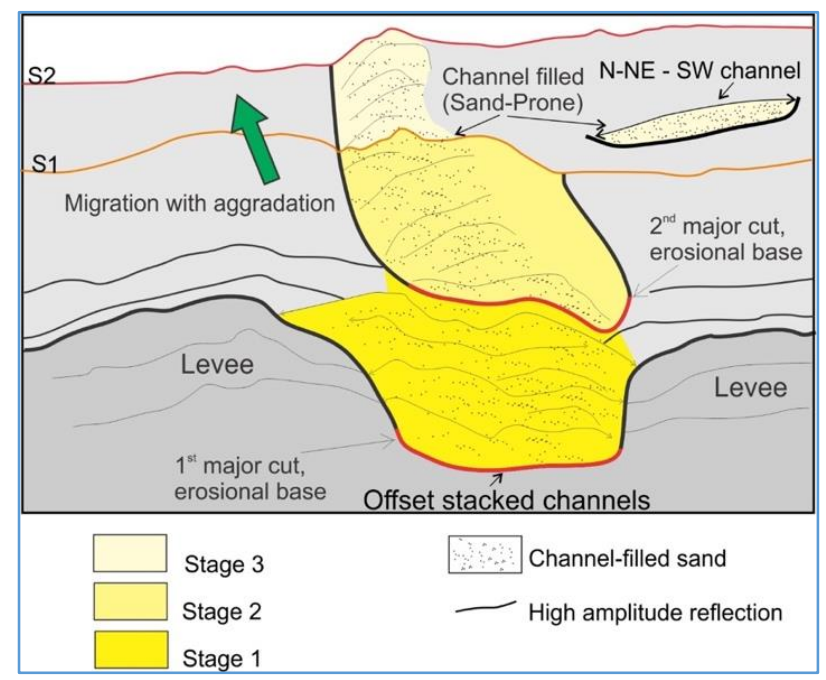

Fig. 6. Line drawing the Miocene channels. The channelized deposits are expressed as high amplitude reflections that are most likely indicative of the presence of sandy deposits.

\section{Conclusions}

In general, submarine channels have developed in the northern part of the study area during the Miocene time. There are two-channel systems in the study area, including the offset stacked channel and North-Northeast-Southwest channel. The offset stacked channel is a large-scale, long-term evolution in the entire Miocene time. The channel is about $3 \mathrm{~km}$ wide and $500 \mathrm{~ms}$ TWT thick, extending from east of c. $20 \mathrm{~km}$ long. There are three stages of channel evolution. Stage one is at the largest scale and highest energy flow, which is gradually reduced in channel size and flow energy in the later stages. The long-term development of the channel indicated a consistent sediment source supplying the area during the Miocene time. At the end of Miocene time, corresponding to stage three of the offset stacked channel, the north area has a new channel development, indicating a new sediment source from the northeast. The channel is c. $3 \mathrm{~km}$ wide, $20 \mathrm{~km}$ long, $50 \mathrm{~ms}$ TWT thick. Almost all the channel fills are 
characterized as high amplitude reflections which are interpreted to be sandy deposits. This channel sand gives a great reservoir potential as its large scale resulting from long term evolution. Besides, the Late Miocene uplift has created a compacted offset stacked channel with the anticline form. This brings a significant hydrocarbon trap potential for the study area.

\section{Acknowledgements}

I would like to thank Sterling Energy Company for providing the 3D seismic data for this study. I am grateful to Schlumberger for software support. I also gratefully thank the reviewers for reviewing the manuscript and giving very constructive and helpful comments. The authors are very grateful to the Editor in Chief Prof. Dr. Salih M. Awadh, the Secretary of Journal Mr. Samir R. Hijab and the Technical Editors for their great efforts and valuable comments.

\section{References}

Abreu, V., Sullivan, M., Pirmez, C. \& Mohrig, D. 2003. Lateral accretion packages (LAPs): an important reservoir element in deep water sinuous channels. Marine and Petroleum Geology, 20, 631-648.

Dailly, P., Lowry, P., Goh, K., Monson, G. 2002. Exploration and development of Ceiba Field, Rio Muni Basin, Southern Equatorial Guinea. The Leading Edge, 21, 1140-1146.

Gay, A., Lopez, M., Cochonat, P., Sultan, N., Cauquil, E., Brigaud, F. 2003. Sinuous pockmark belt as indicator of a shallow buried turbiditic channel on the lower slope of the Congo Basin, West African Margin. Geological Society, London, Special Publications, 216, 173-189.

Gee, M., Gawthorpe, R. 2006. Submarine channels controlled by salt tectonics: Examples from 3D seismic data offshore Angola. Marine and Petroleum Geology, 23, 443-458.

Gee, M., Gawthorpe, R., Bakke, K., Friedmann, S. 2007. Seismic geomorphology and evolution of submarine channels from the Angolan continental margin. Journal of Sedimentary Research, 77, 433-446.

Imran, J., Parker, G., Pirmez, C. 1999. A nonlinear model of flow in meandering submarine and subaerial channels. Journal of Fluid Mechanics, 400, 295-331.

Kolla, V., Posamentier, H. \& Wood, L. 2007. Deep-water and fluvial sinuous channels - Characteristics, similarities and dissimilarities, and modes of formation. Marine and Petroleum Geology, 24, 388-405.

Lawrence, S. R., Munday, S., Bray, R. 2002. Regional geology and geophysics of the eastern Gulf of Guinea (Niger Delta to Rio Muni). The leading edge, 21, 1112-1117.

Lazim, A. A., Hussein, M. A., Khazaal, H. F., 2020. The effect of west qurna oilfield on the part of euphrates river, northern basra governorate, Iraq: geomorphic and structural geology integrated analysis. Iraqi Geological Journal, 90-103.

Le, A. N. 2021a. Characterization and distribution of Cenozoic Polygonal Fault, case studies in West Africa Continental Margin and Vietnam continental margin. Iraq Geological Journal 54.

Le, A. N. 2021b. Striations at The Base of The Paleo-Fan and Channel Revealed by 3D Seismic Data, Offshore Cameroon. Indonesian Journal on Geoscience, 8, 101-107.

Le, A. N., Huuse, M., Redfern, J., Gawthorpe, R. L., Irving, D. 2015. Seismic characterization of a Bottom Simulating Reflection (BSR) and plumbing system of the Cameroon margin, offshore West Africa. Marine and Petroleum Geology, 68, 629-647.

Macauley, R. V., Hubbard, S. M. 2013. Slope channel sedimentary processes and stratigraphic stacking, Cretaceous Tres Pasos Formation slope system, Chilean Patagonia. Marine and Petroleum Geology, 41, 146-162.

Posamentier, H. W., Kolla, V. 2003. Seismic geomorphology and stratigraphy of depositional elements in deepwater settings. Journal of sedimentary research, 73, 367-388.

Zhao, X., Qi, K., Liu, L., Gong, C., Mccaffrey, W. D. 2018. Development of a partially-avulsed submarine channel on the Niger Delta continental slope: architecture and controlling factors. Marine and Petroleum Geology, $95,30-49$. 